\title{
Maximum Power Extraction from Photo Voltaic Cell Based on MPPT System with GWO Algorithm
}

\author{
Bala Murali Pydi, Yogesh Kumar Nayak and Umesh Kumar Sinha \\ Department of Electrical and Electronics Engineering, National Institute of Technology, \\ 831014 Jamshedpur, Jharkhand $(\mathrm{JH})$, India
}

\begin{abstract}
Maximum Power Point Tracking (MPPT) is a technique utilized in power electronic circuits to extract maximum energy from the Photovoltaic (PV) systems. In the recent decades, photovoltaic power generation has become more important due its many benefits such as needs a few maintenance and environmental advantages and fuel free. To capture the maximum power from the sun light in order to generate maximum power from the inverter, control system must be an equally efficient with the well designed power electronic circuits. The system includes a solar panel, MPPT controller a DC-DC converter and a three level bridge inverter. In this research maximum power of PV panel different MPPT techniques and GWO technique is used in P\&O base model. Then power conversion process DC/DC converters are widely used in photovoltaic generating systems as an interface between the photovoltaic panel and the load after getting maximum power, inverter to convert power in DC-AC connected to grid. This proposed work compared to the other optimization techniques. Simulation and experimental results for residential solar system with power electronic converters and analysis have been presented in this study in order to prove the proposed algorithm.
\end{abstract}

Key words: PV panel, solar energy, maximum power point tracking, boost converter, inverter, GWO algorithm

\section{INTRODUCTION}

Now a days, the renewable energy sources play a very significant part in the domain of electric power production. In this regard, several renewable sources like the solar energy, wind energy, geothermal and so on are exploited fully for the purpose of electric power production out of which solar energy emerges as a convincing candidate vis-a-vis others (Vishnukumar and Uma, 2013). In the present day scenario the non-conventional energy sources of energy have emerged as the shining stars in the galaxy of energy sources, evidently rocked by their gigantic consumption and the swallow up of the fossil fuel. In addition, the solar energy may be deemed as the utmost equipped and accessible source of energy with no overheads (Rathnakumar and Ankaiah, 2013). As a result, solar arrays output power varies with the load changes in evaluating external circumstances, though the power point is restricted to a peak value followed in suit by the voltage and current with their summit values depending upon the power point. Two sparking qualities which have a telling effect on the generated PV power embrace the array Temperature (T) and irradiation (S) (Sarvi et al., 2013). Further the Maximum Power Point Tracking (MPPT) is effectively employed to achieve the utmost power from the captioned technologies. Various applications highly benefited by the MPPT comprise the setting up of the power on the grid, the charging of batteries or the powering of an electric motor (Karanjkar et al., 2014). With an eye on assuring the superb efficacy of the PV system a host of MPPT techniques have been spearhead a few of which include the Fractional Open-Circuit Voltage (FOCV), Fractional Short-Circuit Current (FSCC) fuzzy logic, neural network, Perturbation and Observation $(\mathrm{P} \& \mathrm{O})$ and the incremental conductance (Tey and Mekhilef, 2014). In fact, the solar energy has surfaced as a very powerful and innovative form of energy. The grid-linked Photovoltaic (PV) mechanism does away with necessity for huge and loss-incurring batteries there by paving the way for the ultimate cut back in communication losses. It is a cause of concern that the conservative sources of energy appear to bid a hasty good-bye to the human race. This phenomenon has consequently led to the depletion of scarce sources and the attendant rocking costs of energy. In this alarming scenario a ray of

Corresponding Author: Bala Murali Pydi, Department of Electrical and Electronics Engineering, National Institute of Technology, 831014 Jamshedpur, Jharkhand (JH), India 


\section{J. Eng. Applied Sci., 14 (6): 1743-1748, 2019}

hope for the human race is the photovoltaic energy which has appeared as a god-send gift and an appealing alternate source (Manohar and Rani, 2012). The vital issue behind the generation of $\mathrm{PV}$ is the fact that exterior circumstances tend to have an incredible impact on output power. Thus, any variation in the temperature and light intensity leads to considerable change in the output power. Further, colossal investment with inferior effectiveness is the other lacuna faced (Wang et al., 2011). The conversion efficiency of the electric power generation tends to be abysmally low plunging even to the range of $9-17 \%$ particularly in the back drop of inferior irradiation scenarios. Moreover, the quantity of electric power produced by the solar arrays fluctuates in tandem with the change in climate (Alsadi and Alsayid, 2012). In this regard, the solar radiation is home to photons of various energies of which some are engrossed at the p-n junction. It is found that the photons having energies less than the band gap of the solar cell fail to deliver the goods and hence, no voltage or current could be produced (Varshney and Tariq, 2014). The cardinal challenge addressed by the MPPT is to instinctively evaluate the PV output voltage or output current in which the PV array is capable of ushering in the peak output power against the backdrop of a particular temperature and irradiance. The achievement of peak power necessitates load-line fine-tuning under alteration in the irradiation level and the temperature (Eltawil and Zhao, 2010). It is pertinent to note that now a days a flood of MPPT techniques have been green-signaled and widely employed (Hohm and Ropp, 2003). Thus, it is possible to categorize the captioned methods in accordance with the traits like the types of sensors required, convergence speed and cost, degree of efficiency, performance hardware requirement and status (Kottas et al., 2006). A host of control techniques like the adaptive control, the neural control and the fuzzy control have been effectively evaluated (Krohling and Rey, 2001). Standing out among them is the charismatic Proportional-Integral-Derivative (PID) controller which has been offered red carpet welcome in the industry as a whole in view of its sterling qualities of easy configuration and vigorous performance in an extensive gamut of functional scenarios (Gaing, 2004). The innovative PI controller has been launched and replicated with the bode evaluation technique by means of a small signal model of boost converter and investigated for several specific values of solar radiation and temperature (Karanjkara et al., 2014). The general innate deficiencies of the wind power generation and solar photovoltaic systems are their erratic behavior which tend to turn them unpredictable (Shankar et al., 2013). In this regard, the overall PV system (Array, converter, etc.) is well-geared to function with supreme efficacy thereby turning out the peak output power. Though the site of the MPP is unknown it is possible to locate it by means of calculation models or by search algorithms. Hence, MPPT methods are essential to preserve the PV array's operating point at its MPP (Chafle and Vaidya, 2013). By means of evaluating the response of perturbation on output power of PV panel, the course of change like the decline or increase of the control signal is calculated. Hence, taking a path different from that of the offline techniques when a perturbation is performed the control signals are not at all deemed as consistent. Therefore, tracing the peak output power embraces oscillations around the optimum value (Joshi and Shah, 2013).

\section{MATERIALS AND METHODS}

System understudy: The stand-alone PV systems which are designed to operate independently from the electric utility grid are generally sized to the electrical loads. The purpose of this research is to develop the model for grid-connected PV systems the power (DC-DC) conversion process buck boost converter is used. For maximizing the power in solar panel MPPT system in general is intended to extraction of maximum power from the PV panel. This maximum power process Perturb and Observe (P\&O) and Incremental Conductance (INC) with optimization techniques are used to optimize parameters by using Grey Wolf Optimization (GWO) technique compared to other optimization techniques. After getting minimum error value the power converted to the DC-AC process three level bridge inverter is used. This maximum $\mathrm{AC}$ power connected to the grid analysis the process. This proposed method based minimizes the voltage drop and maximize the power of solar panel and also this analyzed, the proposed block diagram shown in Fig. 1.

\section{Overview \\ MPPT control: Maximum Power Point Tracking or MPPT is the automatic adjustment of the load of a photovoltaic system to achieve the maximum possible power output. PV cells have a complex relationship between current, voltage and output power which produces a non-linear output. This output is expressed as the current-voltage characteristic of the PV cell. For maximize the power P\&O and $\mathrm{NNC}$ with optimization techniques are used. The proposed GWO technique compared to other optimization technique reduced the error values.}




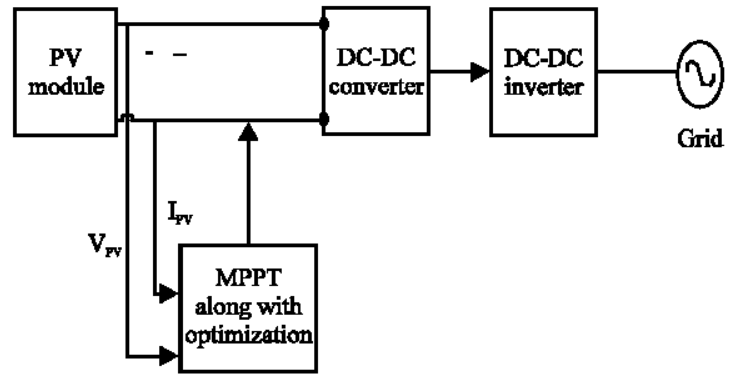

Fig. 1: Block diagram for proposed approach

Perturb and Observe (P\&O) method: In this method a slight perturbation is introduce system. This perturbation causes the power of the solar module changes. The worth of solar photovoltaic module voltage and power at kth instant are kept. Again the solar photo-voltaic power is calculated at next value $(\mathrm{k}+1)$ th instant from the measured value of voltage and current.

Incremental Conductance (INC) method: In incremental conductance method with fixed step size the array terminal voltage is always adjusted according to the MPP voltage it is based on the incremental and instantaneous conductance of the PV module. This method can determine whether the MPPT has reached the MPP and also stops perturbing the operating point. If this condition is not met, the direction in which the MPPT operating point must be perturbed can be calculated using the relationship between voltage and current difference values.

\section{A brief description of Grey Wolf Optimizer (GWO) \\ Initialization: Initialization processes the random solutions the gain parameters values to obtain the minimum error value.}

Fitness evaluation: To localize the fitness in solar panel the maximum power compared to previous power value then calculates the error value with optimal gain parameters:

$$
\mathrm{F}_{\mathrm{i}}=\operatorname{optimal}(\mathrm{u}(\mathrm{t}))
$$

Updating new solution: The best solution (Gain parameter) related on the fitness value has to be found. After that, based on the process given below the position and new solution is updated. As a result, hoard the first three best solutions attained, so far and require the other search agents (Including the omegas) to revise their positions according to the position of the best search agent. For repetition, the new solution is estimated by using the formulae mentioned as:

$$
\begin{aligned}
& D^{\alpha}=\left|C_{1} P_{\alpha}-P\right|, D^{\beta}=\left|C_{1} P_{\beta}-P\right|, D^{\delta}=\left|C_{1} P_{\delta}-P\right| \\
& P_{1}=P_{\alpha}-A_{1}\left(D_{\alpha}\right), P_{2}=P_{\beta}-A_{2}\left(D_{\beta}\right), P_{3}=P_{3}-A_{3}\left(D_{\delta}\right)
\end{aligned}
$$

Investigation and utilization are guaranteed by the adaptive values of $\mathrm{A}$ and $\alpha$ controlling parameters of $\mathrm{A}$ and $\alpha$ permit the GWO to transit them smoothly among the investigation and the utilization. With decreasing a half of the iterations are dedicated to the investigation $(|\mathrm{A}|<1)$ and the other half are devoted to the utilization. Encircling the behavior, the subsequent equations are employed in order to provide mathematical model:

$$
\mathrm{D}=\left|\mathrm{CP}_{\mathrm{P}}(\mathrm{t})-\mathrm{P}(\mathrm{t})\right|
$$

The coefficient vectors are found by the Eq. 3 :

$$
\overrightarrow{\mathrm{A}}=2 \vec{\alpha} \cdot \overrightarrow{\mathrm{r}_{1}}-\vec{\alpha}, \overrightarrow{\mathrm{C}}=2 \cdot \overrightarrow{\mathrm{r}_{2}}
$$

The components of $\alpha$ are linearly decreased from 2-0 over the course of iterations and $r_{1}, r_{2}$ are random vectors in $[0,1]$. The GWO has only two main parameters (A-C) to be adjusted. However, have kept the GWO algorithm as simple as possible with the fewest operators to be adjusted.

\section{RESULTS AND DISCUSSION}

Simulation and experimental tests are carried out to validate the proposed ideas. This maximum power of the PV panel GWO optimization technique is used this proposed model compared to the different techniques in MPPT and optimization techniques. The design and simulation of problem is done in MATLAB 2015 with the system configurations as i5 Processor with 4 GB RAM and the evaluation is done in solar panel maximum power process.

The complete Simulink Model of the proposed research is as shown in Fig. 2. This simulation model consists of solar panel, MPPT block with optimization technique and at the end buck boost converter and finally inverter used converts the DC power AC form. Figure 3 shows the MPPs of the PV panels under the different irradiance.

The maximum output power will be 95 and 114.6 $\mathrm{W}$, respectively when $\mathrm{S}=0.75$ and $0.25 \mathrm{~kW} / \mathrm{m}^{2}$ which 


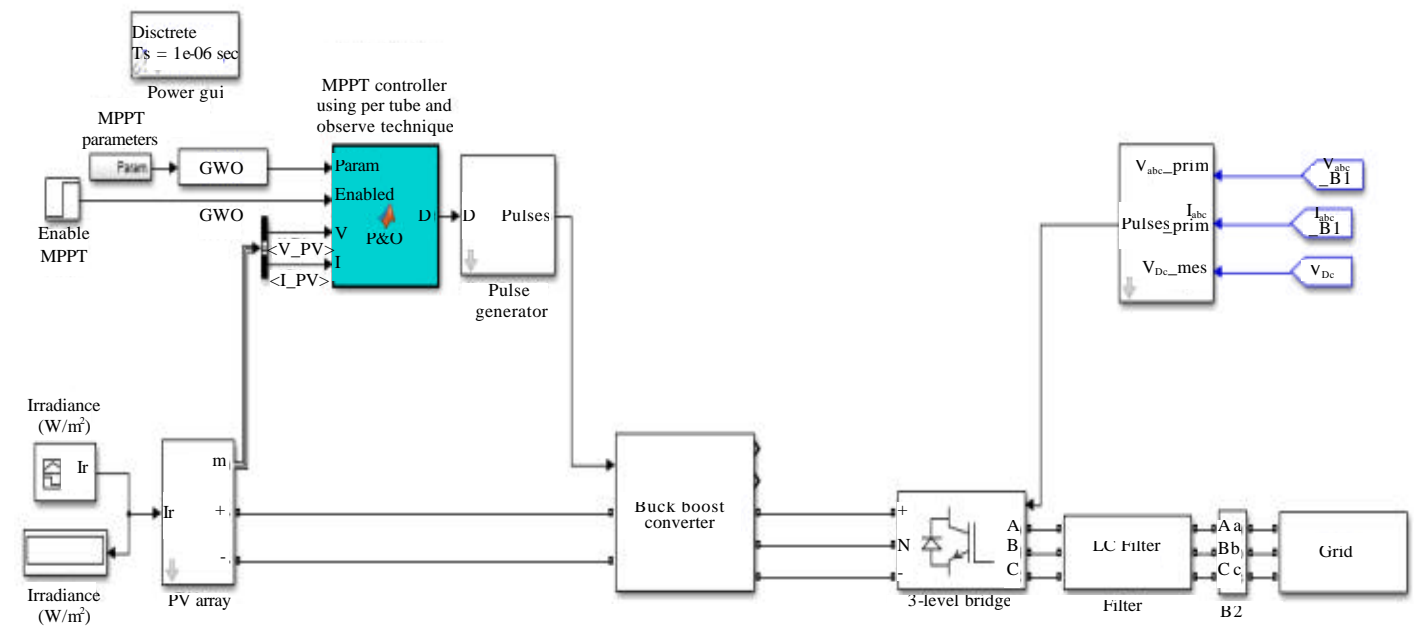

Fig. 2: Simulation model for proposed method
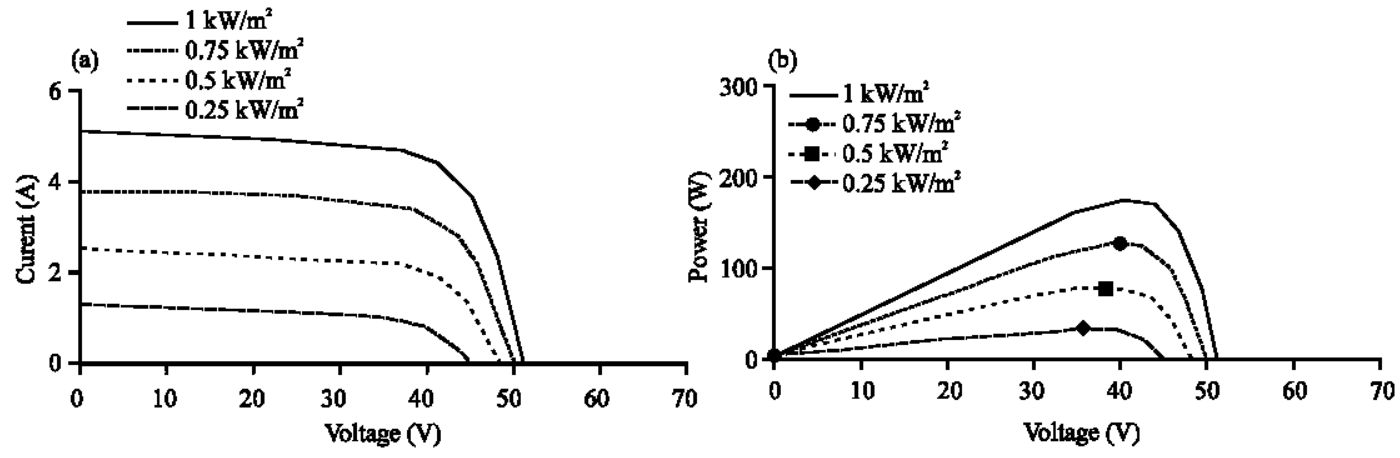

Fig. 3: P-V characteristic under the different irradiance

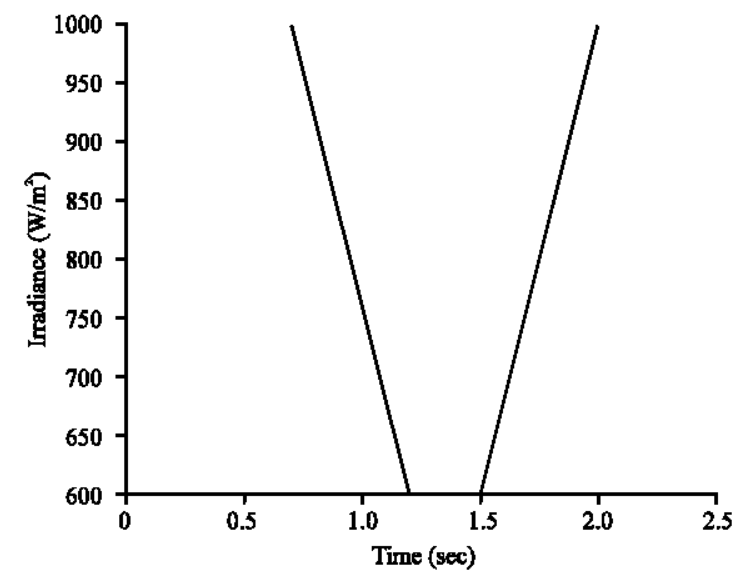

Fig 4: Solar irradiance level

means the total power harvested from the PV system would be $209.6 \mathrm{~W}$ if individual MPPT can be achieved. This higher value is about 1.5 times of the one before. Thus, the individual MPPT control in each string is required to increase the efficiency of the PV system.
Figure 4 illustrates the solar irradiation using maximum power point tracking process. The solar irradiation data with time minutes will be modifying the generated power. Depend on time the irradiation phase is non-linearly changing. If the time is $1.5 \mathrm{~min}$ then the irradiation phase is 600 likewise, the time period based the radiation phase is also changing. For variations in temperature and irradiance, panel output varies severely across the resistive load. The intersection of source and load characteristics can fix MPP. During time based the solar panel irradiance varying linearly if the time increase the irradiance is increasing and decreasing. The method also had a faster response speed than the conventional method.

Figure 5 and 6 show the maximum power comparison in MPPT and three different optimization techniques such as $\mathrm{P} \& \mathrm{O}, \mathrm{INC}, \mathrm{GA}, \mathrm{PSO}$ and proposed GWO optimization techniques. The maximum power attained in GWO technique that is a proposed work maximum power is $112 \mathrm{~W}$ in $0.5 \mathrm{sec}$. Maximize the power from the panel buck boost converter is used to produce the $22.3 \%$ of maximum 


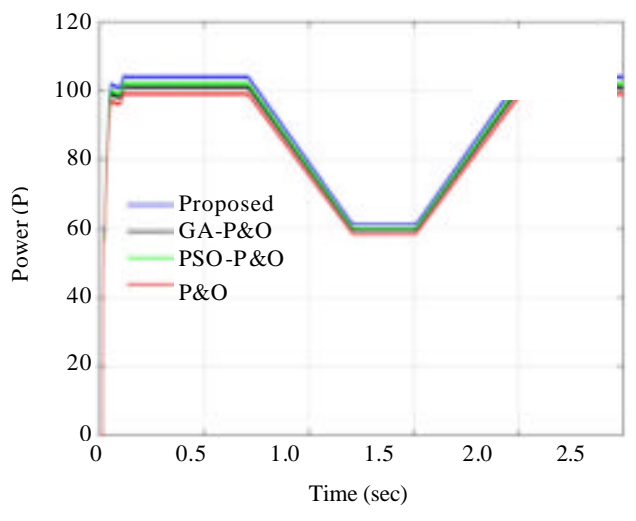

Fig. 5: Comparative analysis for $\mathrm{P} \& \mathrm{O}$

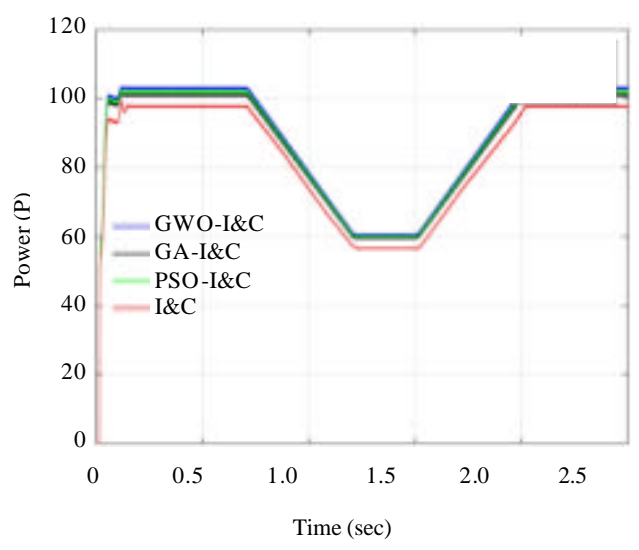

Fig. 6: Comparative analysis for $I \& C$

power from the normal power value. The cascaded H-bridge multilevel inverter has four bridge networks according to switching sequence of inverter switches it produce 3 level staircase sinusoidal output voltage. If the time period $1 \mathrm{sec}$ the power value of different technique is $60 \mathrm{~W}$ then the time period increases that is 1 and $1.5 \mathrm{sec}$ the power value is 117,122 and $123 \mathrm{~W}$ in optimization techniques. MPPT algorithms $\mathrm{P} \& \mathrm{O}$ and $\mathrm{NC}$ the maximum power is $136 \mathrm{MW}$ its compared to proposed method the difference is in this method at $\mathrm{t}=2 \mathrm{sec}$ the tracked power is $65 \mathrm{~W}$ for $700 \mathrm{~W} / \mathrm{m}^{2}$ insulation at $\mathrm{t}=0.2 \mathrm{sec}$ the tracked power is $130 \mathrm{~W}$ for $1000 \mathrm{~W} / \mathrm{m}^{2}$ insulation and at $\mathrm{t}=0.4 \mathrm{sec}$ the tracked power is 80 for $85 \mathrm{~W}$ insulation. By observing the waveforms noticed that the output maximum power will be maintained constant in different insulation levels.

\section{CONCLUSION}

An efficient Maximum power point tracking control algorithm using different optimization technique is discussed in study. Mainly P\&O with GWO optimization algorithm is used to obtain the maximum power point of solar array. Buck boost converter is used to obtain this maximum power point which helps in step down or up the array voltage to the maximum operating point voltage. Dynamic variation of irradiation level is considered as input and tracking efficiency is computed. These process maximum powers of PV panel and produce maximum power value.

\section{RECOMMENDATIONS}

In future, this research PV array at maximum power and thus improves the efficiency of the PV system and the efficiency of the system using different optimization techniques.

\section{REFERENCES}

Alsadi, S. and B. Alsayid, 2012. Maximum power point tracking simulation for photovoltaic systems using perturb and observe algorithm. Intl. J. Eng. Innovative Technol., 2: 80-85.

Chafle, S.R. and U.B. Vaidya, 2013. Incremental conductance MPPT technique FOR PV system. Intl. J. Adv. Res. Electr. Electron. Instrum. Eng., 2: 2720-2726.

Eltawil, M.A. and Z. Zhao, 2010. Grid-connected photovoltaic power systems: Technical and potential problems-A review. Renewable Sustainable Energy Rev., 14: 112-129.

Gaing, Z.L., 2004. A particle swarm optimization approach for optimum design of PID controller in AVR system. IEEE Trans. Energy Conver., 19: 384-391.

Hohm, D.P. and M.E. Ropp, 2003. Comparative study of maximum power point tracking algorithms. Prog. Photovolt: Res. Appl., 11: 47-62.

Joshi, L. and K. Shah, 2013. Incremental conductance based maximum power point tracking for PV multi-string power conditioning system. Intl. J. Emerging Technol. Adv. Eng., 3: 645-650.

Karanjkar, D.S., S. Chatterji, A. Kumar and S.L. Shimi, 2014. Fuzzy adaptive proportional-integral-derivative controller with dynamic set-point adjustment for maximum power point tracking in solar photovoltaic system. Syst. Sci. Control Eng., 2: 562-582.

Kottas, T.L., Y.S. Boutalis and A.D. Karlis, 2006. New maximum power tracker for PV arrays using fuzzy controller in close cooperation with fuzzy cognitive networks. IEEE Trans. Energy Convers., 21: 793-804.

Krohling, R.A. and J.P. Rey, 2001. Design of optimal disturbance rejection PID controllers using genetic algorithms. IEEE Trans. Evol. Comput., 5: 78-82.

Manohar, K. and P.S. Rani, 2012. MPPT and simulation for a grid-connected photovoltaic system and fault analysis. Intl. J. Eng. Sci., 1: 158-166. 
Rathnakumar, S. and B. Ankaiah, 2013. Solar photovoltaic cell by using incremental conductance method with MPPT algorithm. Intl. J. Electr. Electron. Eng., 3: 75-80.

Sarvi, M., M.H. Tabatabaee and I. Soltani, 2014. A fast maximum power point tracking for mismatching compensation for PV systems under normal and partially shaded conditions. J. Math. Comput. Sci., 8: $52-74$.

Shankar, K., M. Thangaraj and A. Abudhahir, 2013. Performance analysis of MPPT algorithms for enhancing the efficiency of SPV power generation system: A simulation study. Proceedings of the 2013 International Conference on Emerging Trends in VLSI, Embedded System, Nano Electronics and Telecommunication System (ICEVENT'13), January 7-9, 2013, IEEE, Tiruvannamalai, India, ISBN:978-1-4673-5300-7, pp: 1-5.
Tey, K.S. and S. Mekhilef, 2014. Modified incremental conductance MPPT algorithm to mitigate inaccurate responses under fast-changing solar irradiation level. Solar Energy, 101: 333-342.

Varshney, A. and A. Tariq, 2014. Simulink model of solar array for photovoltaic power generation system. Intl. J. Electron. Electr. Eng., 7: 115-122.

Vishnukumar, T.M. and G. Uma, 2013. Intelligent controller for maximum power point tracking control of solar power generation system. Intl. J. Eng. Res. Appl., 3: 1965-1969.

Wang, Y., L. Ding and N. Li, 2011. The application of fuzzy parameters self-tuning PID controller in MPPT of photovoltaic power system. Proceedings of the 2011 International Conference on Transportation, Mechanical and Electrical Engineering (TMEE'11), December 16-18, 2011, IEEE, Changchun, China, ISBN:978-1-4577-1700-0, pp: 1129-1132. 